\title{
A Review of Dose Rate Meters as First Responders to Ionising Radiation
}

\author{
Aqeel Ahmad Akber*, Matthew Benfield Wiggins \\ Safe Radiation, Unit 19, 8 St Jude Court, Browns Plains Qld 4118, Australia
}

Background: Dose rate meters are the most widely used, and perhaps one of the most important tools for the measurement of ionising radiation. They are often the first, or only, device available to a user for an instant check of radiation dose at a certain location. Throughout the world, radiation safety practices rely strongly on the output of these dose rate meters. But how well do we know the quality of their output?

Materials and Methods: This review is based on the measurements 1,158 commercially available dose rate meters of 116 different makes and models. Expected versus the displayed dose patterns and consistency was checked at various dose rates between $5 \mu \mathrm{Gy} \cdot \mathrm{h}^{-1}$ and $2 \mathrm{mGy} \cdot \mathrm{h}^{-1}$. Samples of these meters were then selected for further investigation and were exposed to radiation sources covering photon energies from $50 \mathrm{keV}$ to $1.5 \mathrm{MeV}$. The effect of detector orientation on its reading was also investigated. Rather than focusing on the angular response distribution that is often reported by the manufacturer of the device, this study focussed on the design ergonomics i.e. the angles that the operator will realistically use to measure a dose rate.

Results and Discussion: This review shows the scope and boundaries of the ionising radiation dose rate estimations that are made using commonly available meters. Observations showed both inter and intra make and model variations, occasional cases of instrument failure, instrument walk away, and erroneous response.

\section{Invited Paper}

Received September 28, 2019

Accepted October 3, 2019

\section{Corresponding author:}

Aqeel Ahmad Akber

Safe Radiation, Unit 19, 8 St Jude Court, Browns Plains Qld 4118, Australia

E-mail: aqeel.akber@saferadiation.com

This is an Open-Access article distributed under the terms of the Creative Commons Attribution NonCommercial License (http://creativecommons.org/ licenses/by-nc/4.0) which permits unrestricted noncommercial use, distribution, and reproduction in any medium, provided the original work is properly cited.

Copyright $\odot$ 2019The Korean Association for Radiation Protection

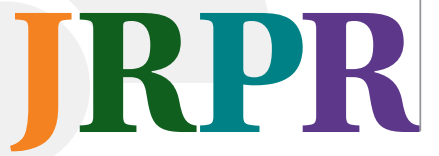

Conclusion: The results indicate the significance of selecting and maintaining suitable monitors for specific applications in radiation safety.

Keywords: Gamma Radiation Dose Rate Meters, Radiation Safety, Radiation Detector Orientation, Radiation Detection Energy Response

\section{Introduction}

The significance of ionising radiation monitoring equipment has been emphasised both internationally and nationally in Australia [1-3]. A publication by the International Atomic Energy Agency (IAEA) mentions monitoring of the workplace as a requirement under the application of the principles of radiation protection. It states that "registrants and licensees, in cooperation with the employers where appropriate, shall establish, maintain, and keep under review a programme for workplace monitoring under the supervision of a radiation protection officer or qualified expert."

Portable external gamma radiation survey meters (commonly referred to as dose rate meters) are extensively used for ionising radiation monitoring. In the hands of a well-trained operator, a dose rate meter has played an important role in maintaining a radiation safe practice, even identifying an emergency situation and averting a serious 
radiation accident $[4,5]$. Several codes of practice and safety guides in Australia mention (i) that the regulators should ensure through the radiation management plan approval, the availability of suitable dose rate meters, (ii) minimum device characteristics such as dose rate range and alarms, and (iii) calibration check frequency; etc. Specific requirements of dose rate meters and their characteristics in practices involving nuclear medicine [6], fixed gauges [7], naturally occurring radioactive materials [8], and industrial radiography [9] are some examples. It is important to select a dose rate meter with characteristics which are suitable for its intended use. IAEA, for example, mentions that a dose rate meter which is commonly used for conventional radioactive source radiography may unsuitable for use with pulsed X-ray radiography sources or higher photon energy linear accelerators [10].

The data for this review was obtained from a laboratory which holds a certificate of reference standard of measurement in Australia, the facility being traceable to the Australian primary standard of radiation exposure. Each year, the lab checks a large number of commercially available dose rate meters which are in use by different entities Australia wide involved in activities such as human and veterinary health, emergency services, education and research, chemical analysis, mineral exploration and industrial processing, industrial radiography, scrap material handling, and check monitoring etc. A large number of commercially available dose rate meters which are in use by a diversity of radiation practices thus provide an overall view of their status and behaviour. This paper presents some aspects of observations which have been divided in the following five sections:

- Displayed dose rates versus the expected dose rates

- Measurement of ambient background (lab environment)

- Effect of device orientation on the displayed dose rate

- Photon energy dependence of the displayed dose rate

- Failures and inadequacies

\section{Observations and Discussion}

The meters displayed dose rates in one of the following three quantities and units; dose equivalent as $\mu \mathrm{Sv} \cdot \mathrm{h}^{-1}$, exposure rate in $\mathrm{mR} \cdot \mathrm{h}^{-1}$, or air kerma as $\mu \mathrm{Gy} \cdot \mathrm{h}^{-1}$. A comparison for this review, however, required all values to be in the same units. All data in this paper have been, therefore, converted into the basic unit of air kerma rate in $\mu \mathrm{Gy} \cdot \mathrm{h}^{-1}$.

\section{Displayed versus expected dose rates}

Figure 1 is the response of all functional dose rate meters reviewed for this study. The results cover a total of 1,158 commercially available dose rate meters of 116 different makes and models. The detector response was checked by

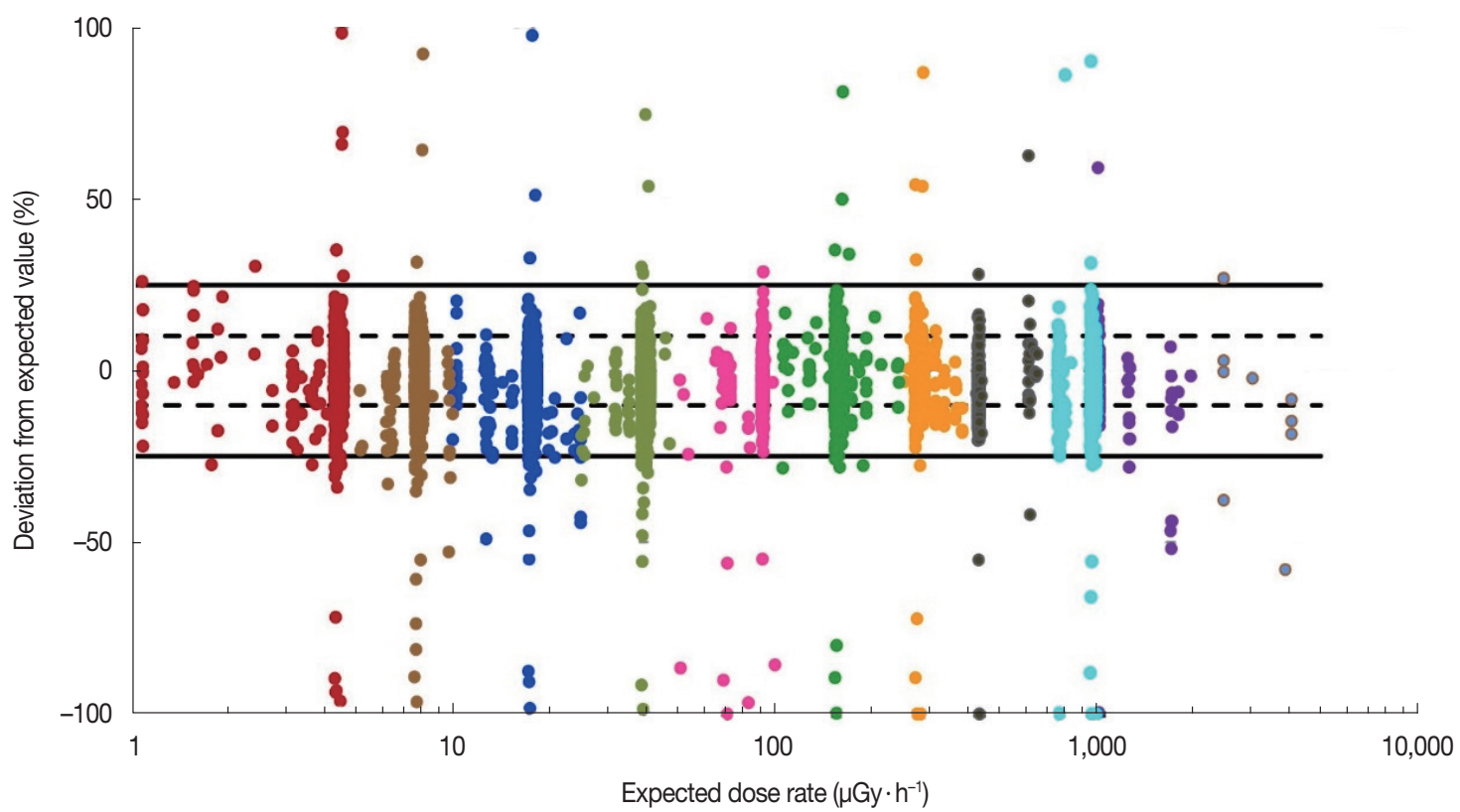

Fig. 1. The observed deviation of the dose rate as displayed by a monitoring device from that expected from a calibrated ${ }^{137}$ Cs source. About $22 \%$ and $3 \%$ of the values lie outside $\pm 10 \%$ deviation (dashed horizontal lines), and $\pm 25 \%$ deviation (continuous lines) respectively. For further statistical analysis, the data have been subdivided into 11 arbitrary windows of the expected dose rate to which the monitoring device was exposed. These data points in these windows have been shown in different colours in the in the figure. 
exposing it in an appropriate orientation at different distances from a ${ }^{137} \mathrm{Cs}$ photon source. As mentioned in the introduction, the expected dose rate is based upon the calibration of the system traceable to the Australian primary standard of radiation exposure [11]. The results have been plotted as the percentage deviation from the expected dose rate versus the expected dose rate in $\mu \mathrm{Gy} \cdot \mathrm{h}^{-1}$. For uniformity in the data set, measured values in other units $\left(\mu \mathrm{Sv} \cdot \mathrm{h}^{-1}\right.$ and $\left.\mathrm{mR} \cdot \mathrm{h}^{-1}\right)$ have been converted to $\mu \mathrm{Gy} \cdot \mathrm{h}^{-1}$ using standard conversion factors; 1.22 Sv/Gy [12], and 114 R/Gy [13]. The percentage deviation $(\delta)$ of the measured dose rate $\left(\dot{H}_{\text {Measured }}\right)$ from the expected dose rate $\left(\dot{H}_{\text {Expected }}\right)$ is calculated as:

$$
\delta=\frac{\left(\dot{H}_{\text {Measured }}-\dot{H}_{\text {Expected }}\right)}{\dot{H}_{\text {Expected }}} \times 100
$$

Each of the 8,077 points in Figure 1 is an average of five readings, taken with all 1,158 meters. Overall, the results are encouraging and suggest a good quality of the performance of radiation monitors which are in use by different organisations Australia wide. Thus, out of the total readings, about $22 \%$ lie outside $\pm 10 \%$ deviation and about $3 \%$ outside $\pm 25 \%$ deviation from the expected value.

For the purpose of further statistical analysis, the results have been divided into 10 different expected dose rate windows of arbitrarily selected width as, $1-5,5-10,10-25,25-50,50-100$, 100-250, 250-400, 400-700, 700-1,000 and 1,000-2,000 $\mu \mathrm{Gy} \cdot \mathrm{h}^{-1}$.
The data also includes 10 readings of $>2,000 \mu \mathrm{Gy} \cdot \mathrm{h}^{-1}$, they are not further analysed due to a small number of readings in this dose range.

Dose rate deviation frequency distributions of all readings $\left(1-2,000 \mu \mathrm{Gy} \cdot \mathrm{h}^{-1}\right)$ and in $1-5,100-250$, and $1,000-2,000$ $\mu \mathrm{Gy} \cdot \mathrm{h}^{-1}$ dose rate windows are shown in Figure 2. One interesting feature of these distributions is a gradual shift towards the negative values of deviation with the increasing dose rate. It may be due to some count rate loss (detection dead time) at increasing photon intensity. As an average, the deviation changes from near $0 \%$ in $1-5 \mu \mathrm{Gy} \cdot \mathrm{h}^{-1}$ dose rate range to about $-7 \%$ in $1-2 \mathrm{mGy} \cdot \mathrm{h}^{-1}$ (Figure 2 inset). Although, individual behaviour of different device models can substantially deviate from this average. Suitable devices should be, therefore, selected depending upon the radiation dose rate range required to be covered for specific applications.

The broadness of frequency distribution in deviation at lower radiation dose rates (Figure 2) is perhaps a consequence of larger statistical variations at lower count rates.

\section{Measurement of ambient background (lab environment)}

All dose rate meters were tested for the ambient background reading in the lab environment. Ambient background photon energy spectrum is likely to be complex due the presence of different naturally occurring radioisotopes and the cosmic radiation, thereby making it harder to apply

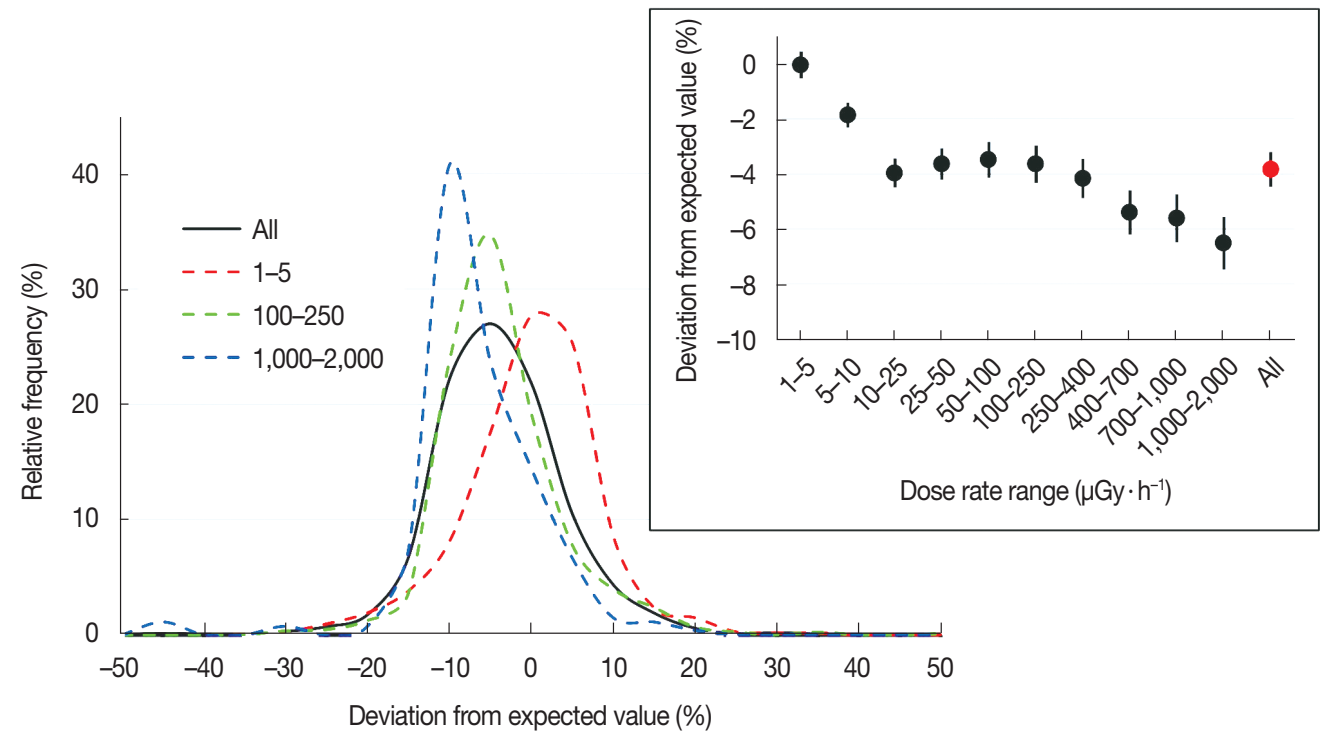

Fig. 2. Frequency distribution of the dose rate meter response deviation from the expected value (as in equation [1]). The results are plotted for all measurements and for the readings in three different dose rate windows, $1-5,100-250$, and 1,000-2,000 $\mu \mathrm{Gy} \cdot \mathrm{h}^{-1}$. The inset shows the average value of deviation in different dose rate windows. 


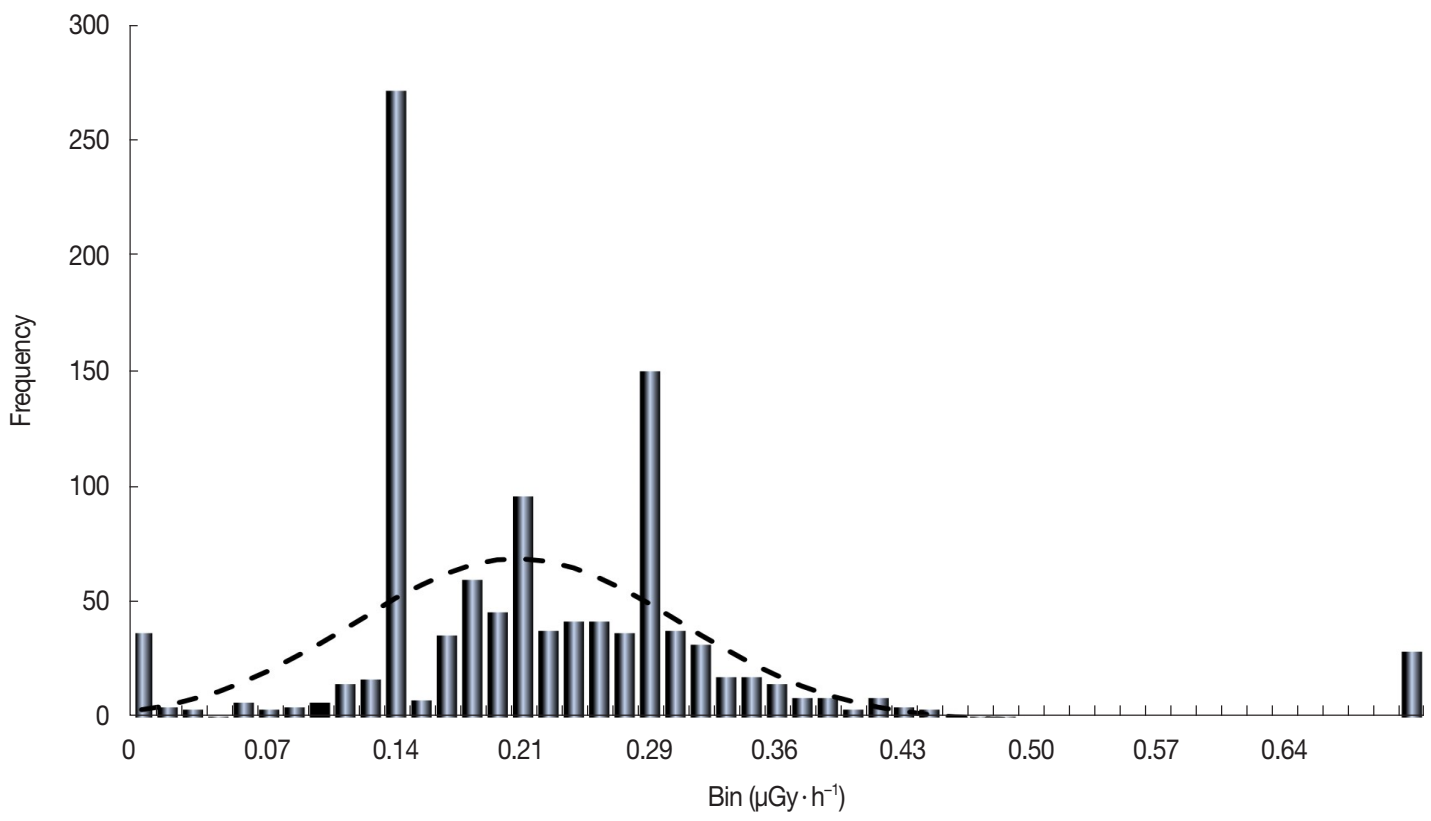

Fig. 3. Frequency distribution of ambient background radiation dose rate as registered be different measurement devices. The dashed line is a normal distribution fit to the data.

an energy dependent factors to convert all data in the same dose rate units. An approximate correction was applied in accordance with the factors suggested by the United Nations Scientific Committee on the Effects of Atomic radiation (UNSCEAR) [14].

Figure 3 shows the lab background frequency distribution of the dose rate registered by the 1,158 devices reviewed in this study. As mentioned, the values include any contribution of the cosmic radiation. A large number of meters read to one decimal point of $\mu \mathrm{Sv} \cdot \mathrm{h}^{-1}$. This has resulted in statistical anomalies in 0.0, 0.14 and $0.29 \mu \mathrm{Gy} \cdot \mathrm{h}^{-1}$ bins.

About $2.5 \%$ of the readings are much higher than the distribution of the remainder $97.5 \%$. However, these outliers in ambient dose rate did not essentially fail in relatively accurate measurements at higher dose rates. Excluding the $2.5 \%$ outliers, the average of all readings is $0.21 \mu \mathrm{Sv} \cdot \mathrm{h}^{-1}$. About $58 \%$ of the meters read within $0.14-0.28 \mu \mathrm{Sv} \cdot \mathrm{h}^{-1}$ range, which is $\pm 25 \%$ of the average.

The dashed line in Figure 3 is a normal distribution fit to the ambient background data, which averages at $0.21 \mu \mathrm{Sv} \cdot \mathrm{h}^{-1}$ with a standard deviation of 0.09 . The wide spread in values shows the inability of most devices to precisely and accurately measure and resolve the dose rates near the ambient background. The devices for environmental level monitoring of dose rates should be selected on the basis of their adequacy for that task.

\section{Device orientation}

A number of manufacturers provide data about the detection system response with respect to the angle of incidence of the beam. For practical applications, though, a user is likely to hold the detector in an orientation such that he or she can conveniently read the displayed dose rate, irrespective of the radiation detector location or direction inside the dose rate meter. As an example, Figure 4A shows three different orientations A, B, and $\mathrm{C}$ in which a user may hold a detector to read the dose rate from a source.

The effect of dose rate meter orientation on the readings of a number of commercially available devices was investigated as part of this review. As indicated above, instead of focusing on the angular response distribution of the device, we investigated the design ergonomics i.e. the angles that an operator will realistically use to measure a dose rate.

Figure 4B shows the deviation in the dose rate reading of 14 different meters, when held in Position B or Position C, relative to that in position A. Each point in Figure $4 \mathrm{~B}$ is based on 70 individual readings, 35 each at either orientation in the dose rate range from $5-1,500 \mu \mathrm{Gy} \cdot \mathrm{h}^{-1}$ due to a $662 \mathrm{keV}$ incident photon beam from a ${ }^{137} \mathrm{Cs}$ point source. The error bars represent the standard error of the mean. Only four (4) of the 14 dose rate metes (about 30\%) display dose rates both in Orientation B and Orientation C which are within $\pm 10 \%$ of that in Orientation A. The results also show that, for some 

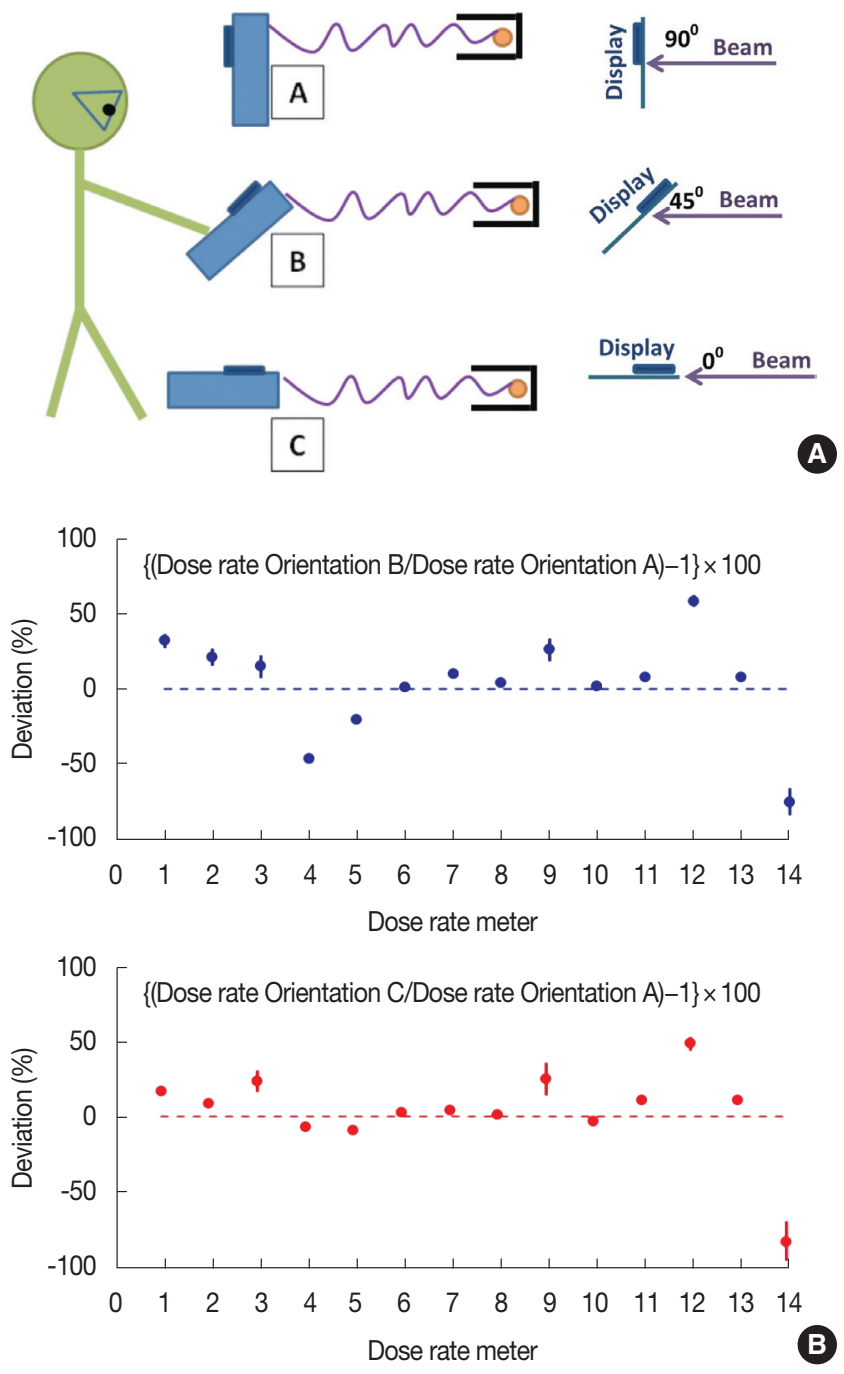

Fig. 4. (A) An operator can ergonomically hold the dose rate meter in limited orientations with respect to the incident beam. The three positions shown in this figure have been used for investigating the effect of detector orientation on the displayed dose rate. (B) Displayed dose deviation with meters in orientations $B$ and $C$ relative to that in orientation $\mathrm{A}$.

commercially available meters, the change in the dose rate reading with respect to orientation could be large - by a factor of 2 to 6 in this study.

\section{Photon energy dependence}

Gamma radiation dose is related to the amount of energy deposited by the photons passing through a material medium. Inside a dose rate meter, the radiation detectors, or the data analysis codes are, therefore, designed with a compensation so that their output should be proportional to the energies imparted by the photons reaching the detection system. Energy response of the dose rate meters is occasionally

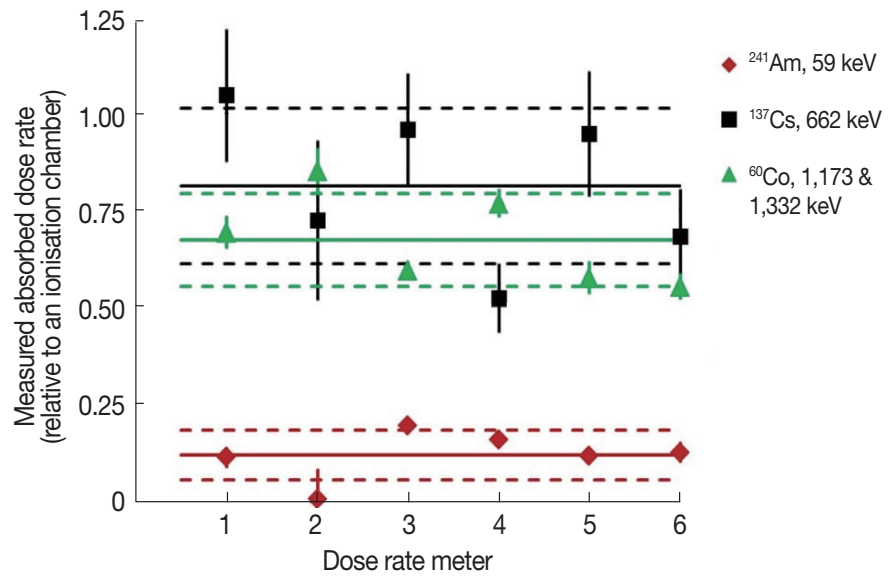

Fig. 5. Measured dose rate (relative scale) by different meters exposed to three different photon energies. The solid line is the average value at each energy, and the dotted lines are drawn at one standard deviation from the average.

checked in the lab. The results of one such experiment have been summarised in Figure 5, where the measured gamma dose rate $\left(\mu \mathrm{Gy} \cdot \mathrm{h}^{-1}\right)$ for six different makes of commercially available dose rate meters has been displayed for gamma emissions from ${ }^{241} \mathrm{Am}\left(\mathrm{E}_{\gamma}=59 \mathrm{keV}\right),{ }^{137} \mathrm{Cs}\left(\mathrm{E}_{\gamma}=662 \mathrm{keV}\right)$, and ${ }^{60} \mathrm{Co}\left(\mathrm{E}_{\gamma}=1,173\right.$ and $\left.1,332 \mathrm{keV}\right)$. Beta emissions from ${ }^{137} \mathrm{Cs}$ and ${ }^{60} \mathrm{Co}$ were attenuated with a $10 \mathrm{~mm}$ plastic sheet.

The results in Figure 5 are on a scale relative to that registered by a thin window ionisation chamber of nearly flat response in this energy range. Meter to meter variations in photon energy dependence are obvious. The results also show a general limitation of several commonly used dose rate meters of poor response at lower photon energies. Overall, in this experiment, relative to a thin window ionisation chamber, the average percentage of dose rate reading of various meters was 12 (0.06), 81 (20), and 67 (12) corresponding to $59 \mathrm{keV}$ from ${ }^{241} \mathrm{Am}, 662 \mathrm{keV}$ from ${ }^{137} \mathrm{Cs}$, and 1,173 \& 1,332 $\mathrm{keV}$ photons from ${ }^{60} \mathrm{Co}$, respectively. The number in the parentheses shows the standard deviation of the data.

\section{Failures and inadequacies}

In addition to the functional devices, for which the analysis has been shown in this paper, about $1.5 \%$ additional meters received for calibration check in the lab were either not performing adequately, or they were regarded inadequate for their intended use.

Such failures include:

- Meter displaying a value in ambient background region but insensitive to above background radiation dose rates. 
- Meter reading unstable i.e., keeps increasing or sometimes decreasing when exposed.

- Display set in incorrect units, e.g. units $\mu \mathrm{Sv} \cdot \mathrm{h}^{-1}$ but the numbers read close to $\mathrm{mR} \cdot \mathrm{h}^{-1}$.

- Display saturates above a certain dose rate without audio or video warning.

Additional inadequacies include:

- Meter unsuitable for the expected application; for example, saturates at higher dose rates, or cannot resolve lower dose rates near ambient background, or the meter may not adequately read X-ray photon dose rates.

- Unrealistic significant figures, e.g. showing up to three decimal places of a $\mu \mathrm{Sv} \cdot \mathrm{h}^{-1}$, which amounts to be 1 $\mathrm{nSv} \cdot \mathrm{h}^{-1}$ resolution even for a short time constant.

- Device not a dose rate meter but a contamination monitor with a poor gamma sensitivity.

\section{Conclusion}

This review of $\sim 1,000$ different of dose rate meters that are used in Australia has shown that it is important to consider the application and the radiation practice when selecting a radiation monitor. Under lab conditions, most of the radiation monitors that are in use in organisations across Australia perform well under calibration, with only $3 \%$ of those measured deviating outside of $25 \%$ of the expected dose rate. However, in real world the ergonomics and the design of the detector can have a significant effect if for an application the most natural way to use the detector means orienting it in a way where it might have poorer performance. Additionally, it is to be acknowledged that dose rate meters may be tuned to perform in a certain photon energy range, and the dose rate range, such that outside of those design parameters they can significantly under report the dose rate. Dose rate meters can fail to read the correct dose rate due to assorted reasons, and therefore should be subject to regular checks for their behaviour.

\section{Acknowledgements}

This work was presented at the 5th Asian \& Oceanic IRPA Regional Congress on Radiation Protection, held in Melbourne 21-23 May 2018. Aqeel Akber gratefully acknowledges receiving IRPA Young Scientist Award and Ronald Rosen Award given to him for presentation of these works.

\section{References}

1. International Atomic Energy Agency. Radiation Protection and Safety of Radiation sources: International Basic Safety Standards. IAEA Safety Standards Series No. GSR Part 3. 2014.

2. International Atomic Energy Agency. Environmental and Source Monitoring for Purposes of Radiation Protection. IAEA Safety Standards Series Safety Guide No. RS-G-1.8. 2005.

3. Australian Radiation Protection and Nuclear Safety Agency (2017) National Directory for Radiation Protection. ARPANSA Radiation Protection Series Publication No. 6. 2017.

4. International Atomic Energy Agency. Lessons Learned from Accidents in Industrial Radiography. IAEA Safety Reports Series No. 7. 1998

5. National Health and Medical Research Council. Code of Practice for the Safe Use of Industrial radiography Equipment. NHMRC Radiation Health Series Publication No. 31. 1989.

6. Australian Radiation Protection and Nuclear Safety Agency. Safety Guide for Radiation Protection in Nuclear Medicine. ARPANSA Radiation Protection Series Publication No. 14. 2008.

7. Australian Radiation Protection and Nuclear Safety Agency. Code of Practice and Safety Guide for Safe Use of Fixed Radiation Gauges, ARPANSA Radiation Protection Series Publication No. 13. 2007.

8. Australian Radiation Protection and Nuclear Safety Agency. Safety Guide for Management of Naturally Occurring Radioactive Material (NORM). ARPANSA Radiation Protection Series Publication No. 15. 2008

9. Australian Radiation Protection and Nuclear Safety Agency. Code of Radiation Protection Requirements for Industrial Radiography. ARPANSA Radiation Protection Series C-4. 2018.

10. International Atomic Energy Agency. Radiation Protection and Safety in Industrial Radiography. IAEA Safety Reports Series No. 13. 1999.

11. Australian Radiation Protection and Nuclear Safety Agency. Certificates of verification of a reference standard measurement, ARPANSA Calibration Report Numbers CAL00619. 2014 and CAL00778. 2017.

12. International Organisation for Standardization. $\mathrm{X}$ and Gamma Reference Radiation for Calibrating Dosemeters - Part 3: Calibration of Area and Personal Dosemeters and the Measurement of Their Response as a Function of Photon Energy and Angle of Incidence. ISO 4037-3. 1999.

13. National Council on Radiation Protection and Measurements. Structural Shielding Design for Medical X-Ray Imaging Facilities NCRP Report No 147. 2004.

14. United Nations Scientific Committee on the Effects of Atomic Radiation. Sources and Effects of Ionizing Radiation. UNSCEAR Report to the General Assembly with Scientific Annexes, Volume I, Annex B. 2000. 